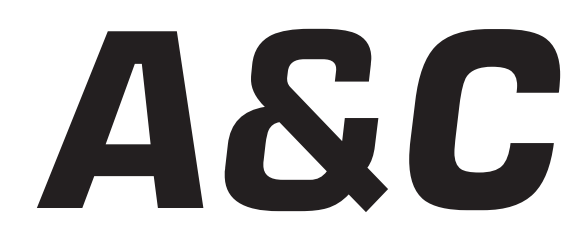

Revista de Direito Administrativo \& Constitucional

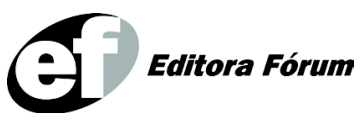

A\&C R. de Dir. Administrativo e Constitucional, Belo Horizonte, ano 6, n. 24, p. 1-246, abr.jun. 2006 


\section{A\&C REVISTA DE DIREITO ADMINISTRATIVO E CONSTITUCIONAL}

\section{IPDA}

Instituto Paranaense

de Direito Administrativo

Direção Geral

Romeu Felipe Bacellar Filho

Direção Editorial

Paulo Roberto Ferreira Motta

Direção Executiva

Emerson Gabardo

Conselho de Redação

Edgar Chiuratto Guimarães

Adriana da Costa Ricardo Schier

Célio Heitor Guimarães

Conselho Editorial

Adilson Abreu Dallari

Alice Gonzáles Borges

Carlos Ari Sundfeld

Carlos Ayres Britto

Carlos Delpiazzo

Cármen Lúcia Antunes Rocha

Celso Antônio Bandeira de Mello

Clèmerson Merlin Clève

Clóvis Beznos

Enrique Silva Cimma

Eros Roberto Grau

Fabrício Motta

Guilhermo Andrés Muñoz (in memoriam)

Jaime Rodríguez-Arana Muñoz

Jorge Luís Salomoni
José Carlos Abraão

José Eduardo Martins Cardoso

José Luís Said

José Mario Serrate Paz

Juan Pablo Cajarville Peruffo

Juarez Freitas

Julio Rodolfo Comadira

Luís Enrique Chase Plate

Lúcia Valle Figueiredo

Manoel de Oliveira Franco Sobrinho

(in memoriam)

Marçal Justen Filho

Marcelo Figueiredo

Márcio Cammarosano

Maria Cristina Cesar de Oliveira
Nelson Figueiredo

Odilon Borges Junior

Pascual Caiella

Paulo Eduardo Garrido Modesto

Paulo Henrique Blasi

Paulo Neves de Carvalho (in memoriam)

Paulo Ricardo Schier

Pedro Paulo de Almeida Dutra

Regina Maria Macedo Nery Ferrari

Rogério Gesta Leal

Rolando Pantoja Bauzá

Sérgio Ferraz

Valmir Pontes Filho

Yara Stropa

Weida Zancaner

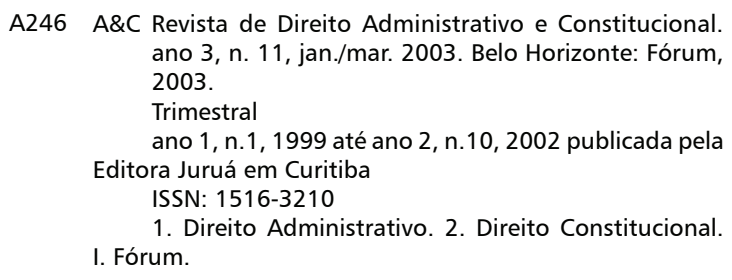

A246 A\&C Revista de Direito Administrativo e Constitucional. ano 3, n. 11, jan./mar. 2003. Belo Horizonte: Fórum, 2003.

Trimestral

ano 1, n.1, 1999 até ano 2, n.10, 2002 publicada pela Editora Juruá em Curitiba

ISSN: 1516-3210

1. Direito Administrativo. 2. Direito Constitucional. I. Fórum.

CDD: 342 CDU: 33.342

(c) Editora Fórum Ltda. 2006

Todos os direitos reservados. É proibida a reprodução total ou parcial, de qualquer forma ou por qualquer meio eletrônico ou mecânico, inclusive através de processos xerográficos, de fotocópias ou de gravação, sem permissão por escrito do possuidor dos direitos de cópias (Lei nº 9.610, de 19.02.1998).

\section{Editora Fórum Ltda}

Av. Afonso Pena, 2770 - 15\%16ªndar - Funcionários

CEP 30130-007 - Belo Horizonte/MG - Brasil

Tel.: 08007043737

Internet: www.editoraforum.com.br

e-mail: editoraforum@editoraforum.com.br
Editor responsável: Luís Cláudio Rodrigues Ferreira Projeto gráfico e diagramação: Luis Alberto Pimenta Revisora: Olga M. A. Sousa

Pesquisa jurídica: Fátima Ribeiro - OAB/MG 74868

Bibliotecária: Alessandra Rodrigues da Silva CRB 2778/MG 6a Região

Os conceitos e opiniões expressas nos trabalhos assinados são de responsabilidade exclusiva de seus autores.

Impressa no Brasil / Printed in Brazil

Distribuída em todo Território Nacional 


\title{
Limites conceituais às exigências de capacitação técnico-operacional em licitações
}

\author{
Floriano de Azevedo Marques Neto \\ Professor Doutor de Direito Administrativo da Faculdade de Direito da Universidade de São Paulo
}

\begin{abstract}
Sumário: 1 Exigências de qualificação e interesses - 2 Natureza e objetivo da qualificação técnico-operacional - 3 A legalidade da exigência específica - 4 O respeito ao artigo $30, \S 5^{\circ}$, da Lei $n^{\circ} 8.666 / 93$ - 5 Síntese e resposta objetiva ao quesito

Palavras-chave: Legalidade. Qualificação técnica. Editais de licitação. Exigência de habilitação. Experiência. Atestados. Certidões. Interesses privados. Capacidade técnico-operacional. Capacidade técnico-profissional. Atestado técnico-profissional. Contrato. Obras rodoviárias.
\end{abstract}

Cuida o presente da análise da legalidade de exigência de qualificação técnica inserida em editais de licitação de um programa para execução de obras de recuperação e melhorias de rodovias.

Divulgados os primeiros editais, houve por parte de alguns potenciais licitantes impugnações e representações contra cláusula editalícia, inclusive perante o E. Tribunal de Contas de Estado de São Paulo. Destes questionamentos restou uma dúvida quanto à legalidade e à constitucionalidade de uma específica exigência de capacitação técnica das empresas potenciais licitantes, concernentes à necessidade de comprovação de experiência anterior na execução de obras com características assemelhadas aquelas postas em disputa.

A Cláusula em referência tem a seguinte formulação básica:

Será admitida a comprovação de aptidão através de certidões ou atestados referentes a obras rodoviárias, em no máximo dois contratos, de forma a atender a todo o conjunto de itens indicado no modelo - Anexo XXV simultaneamente. Deve ser comprovada que a execução das quantidades indicadas no modelo - Anexo XXV foi efetuada no período de 18 meses.

Ressalvado o interregno constante da parte final, que variaria de edital para edital conforme a peculiaridade da execução de cada obra objeto das respectivas licitações (de modo que o período de execução da experiência atestada seja conforme com o prazo de execução previsto para as obras contratadas), no mais a exigência se repete de forma idêntica em A \& C R. de Dir. Administrativo e Constitucional, Belo Horizonte, ano 6, n. 24, p. 59-86, abr./jun. 2006 
todos os demais editais.

Enseja o presente estudo o fato de que, no bojo dos questionamentos antes referidos, ter sido manifestada, no Plenário do E. TCE, posição preliminar no sentido de considerar tal exigência desconforme com o regramento legal das licitações. Segundo me é relatado, a inclinação pela irregularidade da exigência decorreria do entendimento de que as exigências constantes desta cláusula, quando tomadas no seu conjunto, assumiriam caráter restritivo a contrariar o disposto no artigo $30, \S 5^{\circ}$, da Lei $\mathrm{n}^{\mathrm{o}}$ 8.666/93 (Lei de Licitações).

Ainda segundo me é informado, não houve ainda decisão definitiva do E. Plenário do TCE sobre a regularidade da cláusula, porquanto o julgamento restou sobrestado por pedido de vistas. Estando pendente de decisão a matéria, surge o presente trabalho com o fito de verificar se a exigência de qualificação em apreço é ou não lícita, ou se merece reparos para adequá-la ao regime legal vigente.

Nestes termos, um quesito apenas há de ser respondido, formulado nos seguintes termos:

1. A exigência de qualificação técnica inserida nos editais para contratação de obras de melhorias rodoviárias correspondente à demonstração de experiência anterior na execução de itens de serviços realizados em obras rodoviárias, simultaneamente em número limitado de contratos e em período determinado é compatível com o regime da Lei de Licitações, especialmente com o seu artigo 30, $§ 5^{\circ}$ ?

A abordagem do assunto, obviamente, não envolve adentrar no juízo técnico dos itens de serviços cuja demonstração de experiência se exige. Tal avaliação demandaria conhecimentos de engenharia que despossuo. Contudo, não me parece haver dúvidas quanto à conformidade técnica dos itens exigidos, sua adequação e razoabilidade em face do objeto licitado, pois, segundo me é relatado e se depreende dos documentos que me foram oferecidos, o questionamento de mérito quanto a estas exigências já foi afastado pelo próprio Tribunal de Contas.

Para chegar à resposta ao quesito formulado, devo seguir o seguinte itinerário. De início, imagino necessário formular uma breve nota acerca das exigências de qualificação em face dos interesses dos agentes econômicos em fornecer para o Estado (tópico 1). Depois, deverei abordar, também brevemente, a natureza e os objetivos da chamada capacidade técnico-operacional, especialmente vis a vis da capacidade técnico-profis- 
sional, e os requisitos que, inadmissíveis em uma, tornam-se admissíveis em outra (tópico 2). De conseguinte, enfrentarei as exigências postas no item hostilizado, verificando sua aderência ou não ao regime legal (tópico 3). Na seqüência (tópico 4), deverei enfrentar o artigo 30, $\S 5^{\circ}$, da Lei de Licitações, para ver como ele respalda ou rejeita a exigência em tela. Após isso, só restará responder ao quesito adrede formulado (tópico 5) e dar por encerrada a tarefa.

\section{Exigências de qualificação e interesses}

1.1 Sempre que a Administração Pública divulga um edital de licitações, ela estará indiretamente arbitrando interesses privados. De um lado, aqueles que possuem maior tradição e experiência num dado mercado de fornecimento de bens, obras e serviços. De outro, aqueles que querem passar a atuar neste mercado específico. A própria definição do objeto a ser licitado (com maior ou menor fragmentação, maior ou menor complexidade intrínseca) já impacta os interesses de mercado, pois define complexidades e abrangências que serão atendidas por uns e não por outros. $\mathrm{O}$ próprio mercado, relevante na dimensão produto, é definido pelo Estado enquanto comprador de utilidades que só ele pode adquirir (os escopos de fornecimento ao Estado, em regra, são-lhe exclusivos).

Pois, sempre que as exigências de um edital são definidas pelo administrador, há perdedores e vencedores no mercado. Aos que já atuam neste segmento específico interessam exigências mais rigorosas que se constituem em verdadeiras barreiras de entrada a novos competidores. Aos entrantes interessa a lassidão das exigências, de modo a que eles possam tentar se habilitar nestas atividades e competir com os já instalados.

1.2 Ambos os blocos de interesses privados (os que querem entrar e os que desejam preservar seus mercados $)^{1}$ são legítimos. Mais do que isso, pode-se dizer que ambos os interesses privados não são de per si contrários ao interesse coletivo. Da mesma forma como o interesse dos entrantes se

\footnotetext{
É interessante notar, se formos pensar as compras governamentais sob o ângulo do direito concorrencial, os mecanismos normalmente admitidos para preservação de mercados (inovação tecnológica, eficiência alocativa, racionalização de processos, política de marketing, etc) têm pequena aplicação, pois, neste segmento, a definição dos produtos e das condições de fornecimento (e por conseguinte a própria definição do mercado na dimensão produto) é do comprador (Estado) e não, como sói nos demais mercados, do vendedor. É o Estado que define o que quer adquirir, com que especificação (projeto básico), que cronograma, etc. A própria parametrização dos insumos e do projeto (essencial para ter objetividade no julgamento) impede que o fornecedor tenha margem de criatividade ou alternativas para se tornar competitivo.
} 
identifica com o interesse público consubstanciado na maior competitividade, o interesse das empresas que já estão consolidadas num dado mercado (obras rodoviárias, construção de aeroportos, de usinas hidrelétricas, de pontes com esta ou aquela técnica construtiva) se identifica igualmente com o interesse público só que agora representado por maior segurança e garantias de boa e confiável execução do objeto.

O particular que impugna um edital por nele encontrar uma exigência que entende abusiva está, por certo, defendendo legitimamente seu interesse particular em disputar o certame e não buscando primordialmente a defesa do interesse público (ainda que indiretamente possa lograr fazê-lo). A Administração que estabelece exigências mais rigorosas de capacitação (desde que estas sejam razoáveis e compatíveis com o objeto, como adiante indicarei) estará, por seu turno, defendendo o interesse público contido na confiabilidade do futuro executante (em que pese, ainda que indiretamente, estar privilegiando o interesse privado das empresas mais antigas, experientes e bem situadas no mercado específico).

1.3 Certo estou que melhor seria se nosso regime de licitações admitisse mecanismos para um melhor equilíbrio entre as duas ordens de interesses. Isso poderia se dar, por exemplo, se admitíssemos que os interessados, que não lograssem comprovar robusta experiência anterior em empreendimentos congêneres ao objeto licitado, pudessem participar do certame desde que apresentassem garantias (um seguro garantia ou uma performance bond em valor correspondente ao montante estimado para o serviço, a obra ou o fornecimento) suficientes para assegurar que, caso não adimplissem suas obrigações, o poder público não ficaria sobremodo prejudicado. Mas nosso regime legal não admite tal alternativa. Portanto, resta à Administração cercar-se de garantias (via exigências de qualificação técnica e econômica, principalmente) de que qualquer dos candidatos a vencer o certame reúne experiência anterior suficiente a predicar sua capacidade de bem executar o objeto.

1.4 Toda exigência de habilitação implica uma restrição ao universo de potenciais participantes. A simples exigência de certidão negativa de falência ou concordata (artigo 31, II, Lei $n^{\circ}$ 8.666/93) exclui empresas que - malgrado capacitadas para executar o objeto - estejam em processo de recuperação judicial. $\mathrm{O}$ mesmo no tocante à prova de regularidade fiscal (artigo 29, III, Lei $\mathrm{n}^{\circ}$ 8.666/93) no concernente às empresas em eventual atraso com o fisco. E assim por diante. Qualquer exigência que se faça

A \& C R. de Dir. Administrativo e Constitucional, Belo Horizonte, ano 6, n. 24, p. 59-86, abr./jun. 2006 
em sede de habilitação é restritiva, no sentido que reduz o universo de potenciais interessados. Qualquer destes requisitos estabelece uma barreira aos que alvitram participar do certame. Não é, pois, o fato de ser restritivo que inquina de ilicitude a exigência. É a irrazoabilidade ou a ociosidade da exigência que a faz ilícita.

1.5 Nada há de inovador ou de doutrinário na minha afirmação. Ela decorre da própria Constituição onde lemos (artigo 37, XXI) que só hão de ser aceitas "as exigências de qualificação técnica e econômica indispensáveis à garantia do comprimento das obrigações". Ou seja, aceitáveis são as exigências que restringem o universo de participantes (todas em certa medida o fazem) desde que haja um nexo de razoabilidade apto a identificar a exigência com a garantia de certeza e segurança de que qualquer dos habilitados que se sagre vencedor poderá bem executar o objeto. Há mais de dez anos pude consignar a esse respeito o seguinte:

Em suma, somente a peça convocatória é que pode estabelecer as regras que determinarão qual o conjunto de entes privados que - se vencedores do certame - terão condições de executar com segurança o objeto licitado. O grifo se justifica. Não basta apenas que a Administração se certifique que o ofertante atua no ramo ou que potencialmente poderia executar o objeto. Quando o poder público contrata, deve fazê-lo com a certeza de que aquele adjudicatário está plenamente qualificado para realizar com plenitude de qualidade e eficiência o objeto que se lhe comete.

Ao agente público é defeso fazer contratações aventureiras, o que lhe torna impositivas as exigências daquele pretenso contratado, quer pela equipe ou equipamentos de que dispõe, quer pela cabal demonstração da capacidade operacional que angariou ao longo da sua atividade específica. ${ }^{2}$

1.6 Segue daí que a decisão estatal entre exigências mais rigorosas (e, portanto, mais restritivas) e um universo maior de potenciais interessados (e, portanto, mais competição) não pode tomar em conta os interesses privados. O simples fato de haver interessados em disputar o objeto não deve ser bastante para se relaxar as exigências de qualificação. A escolha das exigências de qualificação, pautada por certa margem de discricionariedade, deverá estar lastreada num juízo de interesse público amoldado às especificidades do objeto licitado. O que importa dizer que a licitude de certas exigências de habilitação só pode ser aferida diante do caso concreto, diante de um específico objeto e de uma potencial contratação (com suas

\footnotetext{
2 Ver meu MARQUES NETO, Floriano de Azevedo. O Edital: Exigências Possíveis e Necessárias para Licitar. In: GARCIA, Maria (Org.). Estudos sobre a Lei de Licitações e Contratos: contendo a lei de licitações e contratos com anotações e remissões. Rio de Janeiro: Forense, 1995. p. 102.
} 
características específicas de localização geográfica, prazo de execução, tecnologia empregada, materiais a serem utilizados, etc).

Uma simples pavimentação pode ser tomada como uma intervenção de engenharia bastante simples. Porém, se ela for realizada numa estrada em plena selva amazônica, assumirá complexidades justificadoras de exigências de experiências de obras congêneres em florestas tropicais. O plantio de grama parece-me sobremodo singelo. Porém, imagina-se que plantar grama na Escandinávia reveste-se de uma complexidade apta a justificar a experiência nesta atividade em período curto de tempo (o intervalo entre dois longos períodos invernais) além de requerer cuidados invulgares.

1.7 Ou seja, qualquer exigência impõe o afastamento de alguns interessados, sendo em alguma medida restritiva. Isso não a torna de per si ilícita. Porém, a exigência torna-se ilícita se não se justificar à luz do objeto licitado, se não se demonstrar necessária (for ociosa) e suficiente (não for bastante) para garantir que o futuro contratado reúne condições de bem executar o objeto do contrato.

Segue daí que a licitude de uma exigência habilitatória (especialmente no tocante à qualificação técnica e econômica) somente poderá ser aferida em concreto, diante das especificidades do objeto licitado. Exatamente por isso é que se deve ver com alguma relatividade a jurisprudência sobre o tema. Os precedentes das cortes judiciais ou de contas acerca da admissibilidade ou não de exigências de qualificação, especialmente técnicas, podem servir como parâmetros, mas têm sua utilidade mitigada na medida em que cada juízo de aprovação ou reprovação de uma exigência dependerá, sempre, da análise da peculiaridade e especificidade do objeto licitado, tornando relativa a aplicação do precedente para uma nova licitação com objeto não idêntico. Se os precedentes servem de balizas, não podem, contudo, ser transpostos para outros casos pois sempre estarão impregnados da casuística própria do juízo de proporcionalidade diante do caso concreto.

1.8 Em suma, não será o fato da exigência afastar um ou muitos potenciais interessados que a fará írrita ao ordenamento. O interesse destes particulares se resume a poder disputar a licitação, sem se preocupar com garantir a Administração de que a futura obrigação será bem executada. Contudo, será sim a desnecessidade da exigência para a adequada execução do contrato que a fará ilícita. É à luz destes cânones que podemos enfrentar

A \& C R. de Dir. Administrativo e Constitucional, Belo Horizonte, ano 6, n. 24, p. 59-86, abr./jun. 2006 
a questão aqui trazida.

\section{Natureza e objetivo da qualificação técnico-operacional}

2.1 Como é sabido de todos, o texto aprovado pelo Congresso Nacional que viria a ser a Lei $\mathrm{n}^{\circ} 8.666 / 93$ previa duas modalidades distintas de comprovação de capacitação técnica: a capacidade técnico-profissional, demonstrada pelos atestados dos profissionais responsáveis técnicos pela licitante (artigo $30, \S 1^{\circ}$, I); e a capacidade técnico-operacional, aquela comprovada por atestados emitidos em nome da empresa licitante e que vinha previsto no artigo $30 \S 1^{\circ}$, II (dispositivo este que veio a ser vetado pelo Presidente da República). ${ }^{3} \mathrm{O}$ veto, contudo, não logrou vetar a exigência de atestação técnico-operacional, ${ }^{4}$ que remanesceu admitida na lei por força da referência constante do inciso II ao caput do artigo 30 (que alude a comprovação de capacitação técnica para empresas pois só estas podem indicar instalações e equipamentos e possuir equipe a ela vinculada) e à referência do mesmo artigo 30 , agora no $\S 3^{\circ}$ (que expressamente se refere à capacitação operacional).

Quem primeiro, e de forma até hoje inigualável, defendeu a possibilidade de capacitação operacional no regime da Lei $\mathrm{n}^{0}$ 8.666/93 foi Antônio Carlos Cintra do Amaral, que asseverou: "O que foi impedido, pelo veto, de ingressar no sistema jurídico não foi a capacitação técnicooperacional, mas a disciplina dessa capacitação contida na alínea "b", do $\S 1^{\circ}$ do artigo 30 do projeto de lei. É verdade que não existe na lei, em decorrência do veto, a expressão capacitação técnico-operacional, como ocorre com a capacitação técnico-profissional. Mas o conceito de capacitação técnico-operacional ingressou no sistema jurídico por força do inc. II do artigo 30, interpretado em conjugação com o artigo 33, III, que permite o somatório de quantitativos de empresas consorciadas." ${ }^{5}$

\footnotetext{
O texto vetado era o seguinte: "Artigo 30 (...). $\$ 1^{\circ}(\ldots)$ b. quanto à capacidade técnico-operacional: comprovação do licitante ter executado, no somatório de até (3) três contratos, quantitativos mínimos não superiores a $50 \%$ (cinqüenta por cento) daqueles na mensuração e exclusivamente nas parcelas de maior relevância técnica, ou de valor significativo, do objeto da licitação, e a 50\% (cinqüenta por cento) das relações quantitativo / prazo global destas, admitida a soma dos atestados quando referidos a um mesmo período, sem limites de contratos."

4 Ensina Carlos Ari Sundfeld: "Todo o processo legislativo, que culminaria com o diploma atualmente em vigor, foi marcado por vetos do Presidente da República cujo intento manifesto era extirpar, da redação original do projeto de lei, a possibilidade de se requerer a comprovação da aptidão técnico-operacional das licitantes. O fato é que os vetos não lograram concretizar o intento almejado, pois não recaíram sobre os comandos do artigo 30 que, efetivamente, estatuíam essa possibilidade. Hoje, tais comandos continuam a vigorar incólumes. Esta é a posição que os administrativistas, em coro, temos defendido." (Cf. SUNDFELD, Carlos Ari et al. Os Atestados Técnicos na Licitação e o Problema da Cisão de Empresas. Revista Brasileira de Direito Público, 4/57, p. 61).
} 
2.2 Dúvidas não mais há quanto à exigibilidade de comprovação de capacidade técnico-operacional pelos disputantes de licitações públicas. ${ }^{6}$ O que importa para o presente estudo é discernir para que serve tal exigência. Afinal, como mostrei anteriormente, as exigências licitatórias só podem ser admitidas se justificadas para assegurar a boa futura execução do ajuste. Por que então acrescentar à demonstração da capacitação técnico profissional, a comprovação da capacitação técnico-operacional? A resposta é simples: a exigência das duas comprovações de capacidade se deve ao fato de que cada qual se presta a demonstrar uma capacitação distinta e não suprível pela outra.

2.2.1 A capacidade técnico-profissional se presta a comprovar que nos quadros da licitante haja quem seja habilitado a executar algumas atividades específicas, que possa se responsabilizar pelo bom desate delas. O que se afere com a capacidade profissional é a aptidão para executar tarefas, realizar atividades que integram o objeto do futuro contrato. Se a licitante dispõe de profissionais que possuam experiência, mesmo que fragmentariamente, em uma ou mais atividades congêneres àquelas integrantes do objeto licitado, pode-se presumir que ela, se contratada, não terá dificuldades em desempenhar suas obrigações. Mesmo que cada responsável técnico tenha uma só expertise, admite-se que a soma de vários técnicos com conhecimentos parciais seja bastante para assegurar um suficiente acervo de experiências. A capacidade técnico-profissional, pois, se presta a aferir a detenção de conhecimentos técnicos específicos sobre as distintas atividades integrantes do objeto; serve a identificar a pertença de conhecimentos especializados (mesmo que fragmentários) de como se executa cada etapa da obra, do serviço ou do fornecimento que se quer ver realizado no futuro contrato.

2.2.2 Já a capacidade técnico-operacional tem objetivos bastante

\footnotetext{
5 AMARAL, Antônio Carlos Cintra do. Qualificação Técnica da Empresa na Nova Lei de Licitação e Contratos Administrativos (n 8.666/93). Revista Trimestral de Direito Público, 5/42, p. 47.

6 Além de vasta doutrina, veja-se também a jurisprudência: "ADMINISTRATIVO. PROCEDIMENTO LICITATÓRIO. ATESTADO TÉCNICO. COMPROVAÇÃO. AUTORIA. EMPRESA. LEGALIDADE. Quando em procedimento licitatório, exige-se comprovação, em nome da empresa, não está sendo violado o artigo 30, $\$ 1^{\circ}, I_{\text {, }}$ caput, da Lei n 8.666/93. É de vital importância, no trato da coisa pública, a permanente perseguição ao binômio qualidade eficiência, objetivando, não só garantir a segurança jurídica do contrato, mas também a consideração de certos fatores que integram a finalidade das licitações, máxime em se tratando daquelas de grande complexidade e de vulto financeiro tamanho que imponha ao administrador a elaboração de dispositivos, sempre em atenção à pedra de toque do ato administrativo - a lei —, mas com dispositivos que busquem resguardar a administração de aventureiros ou de licitantes de competência estrutural, administrativa e organizacional duvidosa. Recurso provido" (STJ, REsp. 144.750/SP, Primeira Turma, Relator Ministro Francisco Falcão, j. 17.08.2000).
} 
díspares. Por ela não se pretende saber se a licitante possui experiência pontual e fragmentária em atividades que constam do objeto. Aqui o que se quer saber é se o licitante (organizado como empresa) tem capacidade para organizar, gerir, executar e gerenciar o empreendimento (objeto) como um todo. Não se aferem capacidades em separado, mas a aptidão para realizar o todo em complexidade e especificidade compatíveis com o que se alvitra no futuro contrato. Na capacidade operacional não se comprova o conhecimento técnico específico, mas a capacidade gerencial, organizacional, logística e de gestão de um empreendimento dotado de alguma complexidade.

Recorramos de início a um exemplo gastronômico. Um profissional pode comprovar ter conhecimentos e experiência de chef de cuisine; outro pode reunir profundos conhecimentos em pâtisserie; outro ainda demonstrar larga e reconhecida atividade como somelier. Certamente uma boa casa de repasto não pode prescindir dos conhecimentos técnicos (não se diga que gastronomia não envolve conhecimentos técnicos, pois hoje até mesmo de universidade para tanto dispomos) destes profissionais. Porém, a simples reunião destes técnicos não é suficiente para dotá-los da capacidade para operar um sofisticado restaurante. Por quê?

Simplesmente porque aliada à boa técnica destes profissionais há que se ter alguma capacidade técnico-operacional para organizar e gerenciar um restaurante. Contratação e gestão de recursos humanos (auxiliares de cozinha, preparadores, finalizadores, garçons, maitres, faxineiros, etc), logística de compras (evitando perecimento ou falta dos produtos), gerenciamento de demandas (reservas, alocação dos comensais) entre outros tantos fatores constituem a capacidade gerencial, operacional, distinta da experiência necessária para executar cada tarefa isolada do empreendimento. Ambas são importantes, ambas são imprescindíveis. Porém, são distintas e não se confundem.

2.3 Quando estamos diante de empreendimentos mais complexos, como uma obra pública, essa distinção se mostra ainda mais patente. Como nos ensinava Geraldo Ataliba em um de seus últimos trabalhos seminais: "Obras públicas não são bens que se comprem prontos e acabados, mas sim complexos que se obtêm como resultado de organização do trabalho técnico e artístico. A concorrência, portanto, tem em vista não só o resultado final, mas, também todo o processo de realização, que desdobre em estágios, que produzem afinal, ao resultado desejado (obra pública)." 7

No mais das vezes é essencial possuir na equipe disponibilizada

A \& C R. de Dir. Administrativo e Constitucional, Belo Horizonte, ano 6, n. 24, p. 59-86, abr.jun. 2006 
para uma obra um profissional que já tenha executado tal atividade ou saiba realizá-la. Porém, possuir técnicos em fundações, em instalações hidráulicas, elétricas, instalação de elevadores, com experiência em aplicação de uma ou outra técnica de acabamento sofisticada, não significa necessariamente demonstrar capacidade para executar, em sua completude, um prédio de apartamentos com características que o torne complexo. Uma plêiade de bons e experientes profissionais não dota, automaticamente, uma empresa de capacidade para executar uma obra pública. ${ }^{8}$

2.4 Aqui reside um equívoco que ora e vez comete-se. Não há hierarquia de capacitações. Nem a capacidade técnico-profissional é inferior à técnico-operacional, nem o inverso. Uma empresa pode deter a capacidade operacional e ter perdido a profissional por não mais contar com os responsáveis técnicos que haviam se encarregado de executar as tarefas integrantes das obras por ela executadas. Ou uma empresa pode reunir profissionais com capacidade profissional incontroversa, mas nunca ter logrado executar empreendimentos que lhe confiram capacidade operacional. Não há que se falar em superioridade simplesmente porque cada uma destas capacidades se refere a dimensões distintas de experiência. ${ }^{9}$ Obras há que se pode exigir capacidade profissional e prescindir da demonstração da operacional. Outras, o essencial será exigir a operacional e despiciendo (ou de importância menor) será demonstração de capacidade profissional.

Eis aqui o ponto. Disse linhas atrás que o que torna uma exigência lícita ou ilícita é a compatibilidade e aderência com a especificidade do objeto. A necessidade de demonstração de capacidade técnico-profissional advirá de ser o objeto integrado por atividades específicas que tenham,

\footnotetext{
7 ATALIBA, Geraldo. Licitação: Acervo ou Cabedal Técnico e Engenharia. Revista de Direito Público, 41-42/ 127, p. 131.

8 Novamente sirvo-me da Carlos Ari Sundfeld: "O método, por excelência, para verificar se dada empreiteira é ou não capaz de operar eficientemente (isto é, se tem ou não "capacidade técnico-operacional") é a análise de seu desempenho anterior. A razão é simples: essa capacidade envolve um somatório imenso de fatores basicamente imateriais (organização, sistemas gerenciais, técnicas de controle etc.), que não podem ser medidos por ensaios ou vistorias. Só se pode afirmar com algum grau de segurança a capacidade de uma empresa operar eficientemente se ela assim já tiver operado; se ela nunca operou, pode-se por certo antever sua eficiência, mas não pode haver garantias a respeito." (Cf. SUNDFELD, Carlos Ari et al. Os Atestados Técnicos na Licitação e o Problema da Cisão de Empresas. Revista Brasileira de Direito Público, 4/57, p. 61)

9 "Assim sendo, vê-se que são igualmente importantes a presença de profissionais habilitados e a capacidade gerencial da empresa. São igualmente essenciais os atestados de clientes, alusivos ao desempenho anterior, assim como a demonstração de capacidade financeira e econômica da empresa. Verifica-se assim, que a própria Administração Federal — por estas normas — reconhece que o desempenho do trabalho de engenharia não se faz simplesmente pela existência e atuação de profissionais, mas pela soma dos fatores: 1) presença de profissionais habilitados, 2) instrumental e equipamentos, 3) capacidade, idoneidade organização da própria empresa." (ATALIBA, Geraldo. Licitação: Acervo ou Cabedal Técnico e Engenharia.
} 
isoladamente, alguma peculiaridade e complexidade. Já a capacidade técnico-operacional advirá não da dificuldade da execução de cada tarefa específica, mas do fato de que a integração, a articulação, destas atividades torne o empreendimento mais complexo.

2.5 Segue daí que em geral não será razoável exigir que um só profissional reúna a expertise técnico-profissional em todas as especialidades integrantes de uma obra complexa (por exemplo exigir que um único engenheiro demonstre experiência vasta em engenharia civil, elétrica, hidráulica, em sistemas de telecomunicações, etc). No tocante à experiência técnico-operacional ocorre exatamente o contrário.

Pela sua finalidade, o que se quer ver demonstrada é a capacidade da empresa em organizar, gerir e gerenciar articuladamente e com sucesso uma gama ampla de atividades, no mais das vezes distintas. É justamente a necessidade de articular múltiplas e distintas atividades que justifica se exigir demonstração de capacidade técnico-operacional.

2.6 Exatamente por isso o tratamento a ser dado aos requisitos da capacidade técnico-operacional há de ser distinto daquele reservado à capacidade técnico-profissional. Não faz sentido se exigir capacidade técnico-profissional sem atrelar exigências de requisitos que tornem aferível a expertise da licitante em articular todas as atividades compreendidas num dado empreendimento. Daí a razão de serem admissíveis, em sede da capacidade operacional, exigências de quantidades, de circunstâncias geográficas, de cronograma (prazos) de execução ou de intensidade do envolvimento e mobilização dos fatores de produção. Mais do que admissíveis, elas me parecem essenciais para justificar exigências de capacitação operacional. Explico.

2.7 Se aceitamos como válidas e legais as exigências de capacitação técnico-operacional, e hoje insisto que não me parecem mais cabíveis dúvidas neste sentido, ${ }^{10}$ somente podemos justificá-las em concreto se necessárias a aferir a capacidade organizacional da licitante para executar o empreendimento objeto do certame. E isso só será possível se comprovada a capacidade para engendrar a execução articulada (o que exige demonstração de realização de várias das atividades integrantes do

\footnotetext{
10 "Diante, pois, da absoluta inexistência de proibição legal e, mais, da clara autorização contida no artigo 30, caput, II, do Estatuto das Licitações, absurdo imaginar-se que o Administrador, ao inserir cláusula de capacidade técnico-operacional como requisito para a habilitação em processos licitatórios, esteja a lanhar o princípio da legalidade. Muito ao reverso, está ele simplesmente sendo mesuroso ao poder-dever prescrito pela regra já apontada, como aos princípios da eficiência, da isonomia e da moralidade, todos de caráter constitucional." (PONTES FILHO, Valmir. Concorrência de Obra e Serviço de Engenharia: Comprovação de Capacidade Técnico-operacional dos Licitantes. Revista Trimestral de Direito Público, 30/125, p. 130).
} 
objeto), em condições assemelhadas (geográficas, temporais, climáticas, operacionais, logísticas, etc).

Se tais condições não forem relevantes, não haverá sentido em se exigir capacidade operacional. Porém, pretender possível esta exigência desprovida de especificações de prazo, local, quantidades, características qualitativas, seria transformar a exigência em mera formalidade a mais, em simples incremento de restritividade, írrito, pois, ao regime legal. ${ }^{11}$

Como ensina com percuciência Marçal Justen Filho, "[u]ma interpretação que se afigura excessiva é aquela de que a capacitação técnicooperacional não pode envolver quantitativos, locais ou prazos máximos. Ou seja, admite-se a exigência de comprovação de experiência anterior, mas se pró́be que o edital condicione a experiência anterior relativamente a dados quantitativos, geográficos ou de natureza similar." 12

2.8 Analisemos então a exigência de comprovação num mesmo contrato. Esta exigência parece-me descabida em sede da capacidade técnico-profissional pois, nesta, o importante é que o profissional já tenha travado experiências específicas nas atividades compreendidas no objeto. Pouco importante será que as tenha realizado num mesmo contrato ou ao longo de vários cometimentos. Afinal o que se quer saber é se ele (profissional) já realizou aquela específica atividade (atributos de qualidade do que executou).

Contudo, em sede de capacitação técnico-operacional o que se quer (e deve) buscar é a verificação de que a empresa já conseguiu articular um empreendimento com um determinado vulto. Não se quer aferir se ela teve experiência em realizar a atividade de terraplenar, concretar, edificar, montar equipamentos e implementar sistemas. Quer-se sim saber se a empresa já foi capaz de organizar, gerir e articular todas estas atividades num mesmo empreendimento (daí, num mesmo contrato). Se a lógica da capacidade operacional é a integração de atividades, a organização do ataque a elas, seria contraditório admitir a comprovação de tal experiência de forma segregada, fragmentada, desintegrada.

2.9 O mesmo vale para a exigência de quantidades na atestação técnico-operacional. Na atestação técnico-profissional as exigências de quantidades são em regra descabidas, pois o que se quer ver comprovado é a experiência em espécies de atividades, sendo, portanto, relevante a qualidade da atividade e não quantas vezes ela foi realizada. Já na atesta-

\footnotetext{
${ }^{11} \mathrm{O}$ que a faria ilícita não apenas por força do artigo 30, $5^{\circ}$, mas também do artigo $3^{\circ}$ da Lei n 8.666/93.

12 JUSTEN FILHO, Marçal. Comentários à Lei de Licitações e Contratos Administrativos. 8. ed. São Paulo: Dialética, 2000. p. 338
}

A \& C R. de Dir. Administrativo e Constitucional, Belo Horizonte, ano 6, n. 24, p. 59-86, abr./jun. 2006 
ção técnico-operacional o que se quer ver comprovado é a experiência no engendramento de empreendimentos de certo vulto. Daí que as exigências de quantidades não servem para demonstrar quantas vezes um empreendimento foi realizado, mas para se aferir se o vulto do empreendimento é compatível com o objeto licitado. ${ }^{13}$ As quantidades aqui assumem caráter qualitativo, pois refletem o dimensionamento (complexidade) do empreendimento atestado. ${ }^{14}$

Não é por outra razão que a Lei de Licitações (artigo 30, $§ 1^{\circ}, I$ ) veda que para atestado técnico-profissional sejam exigidas quantidades mínimas. No tocante à capacitação técnico-operacional, as quantidades são admitidas e não apenas por não conter a Lei vedação para esta comprovação. Não há restrição pelo fato de que o dimensionamento quantitativo é imprescindível para se verificar se a experiência comprovada tem ou não o vulto compatível com aquele da obra ou serviço objeto da licitação em disputa. A experiência operacional em executar uma barragem com capacidade para um bilhão de metros cúbicos de água certamente não é a mesma necessária para construir uma barragem com um milésimo desta capacidade. A mobilização de pessoal, equipamentos, as interfaces, o tempo de execução, os recursos envolvidos, tudo isso predica uma necessidade de know-how operacional muito mais complexo e sofisticado que numa obra congênere mas de dimensão (o que envolve dimensão quantitativa) mais acanhada.

2.10 Semelhante, se não idêntica, é a exigência de capacidade operacional no aspecto temporal. Se para demonstrar capacidade técnicoprofissional o relevante é ter executado atividade assemelhada qualitativamente, sendo de menor relevo o tempo em que durou a execução, na capacidade operacional o prazo de realização do empreendimento assume caráter central de relevância. Isso porque o cronograma de execução servirá para tornar mais ou menos complexo operacionalmente o empreendimento. Vedar que se considere o período em que foi realizado o empreendimento significa aproximar a capacidade operacional da

\footnotetext{
${ }^{13}$ Neste sentido a jurisprudência: "A conclusão, portanto, é que podem ser estabelecidos quantitativos mínimos nos atestados de capacidade técnico-operacional, entretanto, em cada caso concreto, deverá ser verificado se as exigências estabelecidas são pertinentes e necessárias para que a administração tenha as garantias necessárias que aquela empresa possui as condições técnicas para a boa execução dos serviços. Não posso concordar, portanto, com a determinação proposta pela Secex / BA, no item Il-a (folhas 294/ 295), uma vez que a restrição para a exigência de quantidades mínimas somente diz respeito aos atestados de capacidade técnico-profissional." (TCU, Decisão 1618/2002, Plenário, Relator Ministro Ubiratan Aguiar, j. 27.11.2002).

${ }^{14}$ Cf. SUNDFELD, Carlos Ari. Licitação e Contrato Administrativo: de acordo com as Leis 8.666/93 e 8.883/ 94. 2. ed. São Paulo: Malheiros, 1995. p. 126.
} 
capacidade técnico- profissional e, por conseguinte, tornar a duplicidade de exigências uma restrição desnecessária. É justamente a característica de ser mais ou menos complexa na sua execução (para o que o prazo conta significativamente) que faz necessária a exigência de capacitação operacional, porquanto um prazo mais exíguo fará a mobilização e a logística mais intrincadas.

2.11 Por fim, igualmente ocorre com o aspecto local de execução. Se por vezes este aspecto pode ter importância menor, em outras ele predicará uma complexidade operacional distinta e relevante. Uma simples pintura de paredes é, em essência, uma tarefa pouco complexa. Se realizada numa UTI hospitalar em funcionamento, assume características de complexidade. Tal qual ocorre com o asfaltamento em plena selva tropical do exemplo antes dado.

A aplicação de sinalização vertical numa estrada ainda não aberta ao tráfego tem complexidade bastante menor do que quando a mesma atividade é realizada numa rodovia em plena operação, assumindo dificuldade operacional significativa (desvio ou interdição de tráfego, tempo de cura, sinalização de emergência, informação aos usuários, etc), apta a se constituir em item de comprovação de capacidade técnico-operacional à parte.

2.12 É à luz destas notas que enfrentarei, finalmente, a exigência motivadora do presente trabalho. Tenhamos em mente que ou se rejeita a possibilidade de exigência de demonstração de capacitação técnicooperacional (hipótese hoje praticamente afastada pela doutrina e pela jurisprudência), ou ela é aceita e, em assim sendo, deve vir revestida de exigências atinentes a prazos, quantidades, especificações de local de realização e de dimensionamento do empreendimento (inclusive combinação articulada de experiências técnicas específicas), sem o que a capacidade operacional não traduzirá aptidão para a boa execução do objeto licitado como um todo, transformando-se em exigência inútil e cumulativa, írrita ao regramento constitucional e legal.

\section{A legalidade da exigência específica}

3.1 Chega-se à exigência em apreço. Como já referido, ela, com variações aqui ou ali de edital para edital, tem a seguinte configuração:

b.3) Será admitida a comprovação de aptidão através de certidões ou atestados referentes a obras rodoviárias, em no máximo dois contratos, de forma a 
atender a todo o conjunto de itens indicado no modelo - Anexo XXV simultaneamente. Deve ser comprovada que a execução das quantidades indicadas no modelo - Anexo XXV foi efetuada no período de 18 meses.

Já que não há notícias de crítica quanto à exigência de atestado em nome da empresa e considerando que, segundo nos informam, foram afastadas as impugnações quanto aos itens de comprovação exigidos pelo Anexo XXV, restaria analisar a conformidade legal de três exigências: i) serem os atestados apresentados relativos a obras rodoviárias; ii) terem as obras atestadas sido executadas em até dois contratos simultâneos (agrupo as duas exigências - número de contratos e execução simultânea — pois são duas dimensões da mesma exigência como adiante ver-se-á); iii) e serem elas executadas num prazo máximo (no exemplo 18 meses, mas havendo variação entre os editais do programa de obras) compatível com o prazo de execução previsto em cada edital.

Vejamos cada uma das exigências.

3.2 Obras rodoviárias. O primeiro requisito hostilizado é que as obras atestadas tenham sido realizadas em rodovias. Trata-se de exigência relativa à localização das atividades de comprovação obrigatória (realizadas em rodovias) que diz com um atributo qualitativo das obras. Ninguém olvida que haja compatibilidade entre a exigência (obras rodoviárias) e o objeto dos editais (já que todos têm por escopo obras de melhorias rodoviárias).

A questão que remanesce é saber se a exigência de que a comprovação se dê exclusivamente em obras realizadas em rodovias seria ou não imotivada (pois que, lembremos, todas as exigências de habilitação são, de alguma forma, restritivas ao universo de potenciais licitantes e serão lícitas desde que razoáveis e necessárias). Dito de outro modo, impende verificar se a comprovação de realização destas atividades poderia ou não ser substituída por atestados de intervenções realizadas em vias urbanas, já que não me parece cogitável postular equivalência com atividades realizadas em estradas rurais.

Uma obra rodoviária não é de per si nem mais nem menos complexa de que outra realizada em vias urbanas. Elas são sim diferentes, não intercambiáveis. Os problemas operacionais que se apresentam para uma não se colocam para a outra.

Numa obra urbana, há o problema das interferências do subsolo 
de forma mais acentuada. Há eventualmente problemas de liberação das vias em horários de pico. Há eventualmente questões de segurança relacionadas ao maior acesso da população do entorno ao canteiro de obras. Tem a obra urbana a sua peculiaridade.

Porém, uma obra rodoviária apresenta especificidades que também a dotam de complexidade ímpar. O movimento de uma obra rodoviária é, em geral, ininterrupto. A possibilidade de interdição completa da via, mesmo que por períodos menores é inviável pela ausência de rotas alternativas de acesso. Mesmo que seja possível a interrupção, ela envolve operação de segurança bastante mais complexa. A sinalização das intervenções assume características muito mais sofisticadas e importância destacada, não fosse pelo simples fato de que em rodovias os veículos trafegam em velocidades médias muito mais elevadas (ensejando risco potencial de acidentes muito maiores).

$O$ risco de um degrau numa pista urbana em obras ocasionar uma capotagem é muito menor do que o mesmo desnível numa rodovia. A movimentação de máquinas e pessoal numa obra rodoviária é muito mais complicada que na sua congênere urbana. Um simples replantio de grama num canteiro central de rodovia é mais complexo que num ajardinado ladeado por vias urbanas, pois o deslocamento de pessoas e equipamentos é naquela mais difícil do que nesta. Ademais, a mobilização numa obra em rodovia é distinta de que numa obra urbana porquanto as instalações (canteiro, pátio de máquinas, usina, etc) hão de ser implantadas em região previamente estudada para otimizar o enfrentamento de obras ao longo de todo o eixo da rodovia.

Segue daí ser absolutamente despropositado falar que obras urbanas são mais complexas que as rodoviárias ou vice versa. Elas têm complexidades distintas. Pode ser que uma empresa com rematada experiência em obras urbanas se esboroe numa empreitada rodoviária (o inverso também é possível).

Diante disso, se coloca como absolutamente razoável que a Administração Pública busque se cercar de garantias de que a futura contratada tenha uma mínima (em quantidades menores que aquelas objeto do futuro contrato) experiência em obra do mesmo gênero que a licitada (obra rodoviária). Nenhum exagero, nenhuma desproporcionalidade, nenhum abuso há, pois, na exigência.

3.3 Limitação do número de contratos simultâneos. O segundo

A \& C R. de Dir. Administrativo e Constitucional, Belo Horizonte, ano 6, n. 24, p. 59-86, abr./jun. 2006 
corte de exigências se refere à necessidade de que as atividades identificadas no anexo tenham sido executadas pela licitante em até dois contratos executados simultaneamente. E trato a limitação do número de contratos e a característica de simultaneidade conjuntamente, pois se trata de duas faces da mesma moeda: a exigência de que os quantitativos tenham sido realizados num empreendimento único, envolvendo mobilização concomitante e não se agregando quantidades ao longo do tempo.

Ora, aqui estamos diante da essência do que seja atestação técnicooperacional, consoante já exposto. Nenhuma serventia teria para fins da capacidade operacional aceitar-se a demonstração da licitante de que já executara todos os itens relevantes do objeto isoladamente, cada qual em um contrato. Isso seria suficiente para demonstrar capacidade profissional já que revelaria que alguma vez já executou aquelas espécies de atividades.

Porém, como me esforcei por demonstrar anteriormente, se aceitamos a necessidade de demonstração de capacidade técnico operacional, é para verificar a capacidade de engendrar todas estas atividades de forma articulada, conjugada, num mesmo empreendimento ou pelo menos em poucos que tenham sido realizados a um só tempo, num mesmo período, em uma palavra, simultaneamente.

Recorro a um exemplo que demonstra de forma cabal que a comprovação de realização fragmentária, ao longo do tempo e não num mesmo empreendimento de várias atividades não serve para comprovação de capacidade operacional. Ninguém duvida que a simples troca de pneus é uma atividade que envolve alguma técnica, mas não tem complexidade digna de nota. Da mesma forma, abastecer um veículo de combustível também não traz dificuldade ímpar. Menor complexidade ainda está em dar uma limpada num para-brisa. Porém, ninguém discordará que todas estas atividades realizadas de forma simultânea, em exíguo tempo, num pit-stop de uma corrida de automobilismo se reveste de elevada complexidade operacional, envolve a intervenção de uma equipe bem treinada e articulada, além de um comando gerencial apurado. Ora, simplesmente pretender que seja demonstrada capacidade pela atestação das atividades isoladas (troca de pneus, abastecimento de combustíveis, remoção de resíduos da viseira do piloto) é absolutamente inservível para atribuir capacidade técnico-operacional para uma equipe de corridas.

Mas há mais. Quer me parecer que a exigência de comprovação mediante até dois contratos (dois empreendimentos, seria o mesmo dizer) 
simultâneos é medida de rigor para impedir a desnaturação da comprovação mediante o somatório de indefinidas intervenções. Já se disse mais de uma vez que a complexidade de execução de uma estrada de 1000 quilômetros não é nem de longe idêntica à experiência de executar mil estradas de 1 quilômetro. ${ }^{15}$ A exigência em apreço, aliás, se coloca bastante inteligente, pois admitiria a experiência na execução de duas estradas de $500 \mathrm{~km}$ simultâneas como suficiente para comprovar a tal estrada de $1.000 \mathrm{~km}$.

A exigência se põe, assim, duplamente justificada. A uma, porque serve para atestar a capacidade de mobilização da licitante ou seja, sua aptidão para mobilizar, organizar e gerenciar recursos financeiros, humanos, materiais e equipamentos e logística para executar a um só tempo as atividades exigidas pelo edital, exatamente o âmago da atestação de capacidade operacional. A duas, porque serve para impedir que a comprovação se dê pela soma de várias experiências de complexidade operacional menor, o que seria incompatível com as exigências de capacidade técnico-operacional.

Como assevera, com sua objetividade e contundência inatingíveis, Adilson Dallari "do ponto de vista da capacidade técnico-operacional, a soma das parcelas não é igual ao produto. Dizendo melhor: uma empresa apta para realizar diversas obras pequenas, nem por isso está capacitada para enfrentar uma grande obra, de porte equivalente à somatória do volume das diversas pequenas obras. São diferentes os meios para comprovar aptidão para executar diversas obras simultaneamente, dos meios necessários para enfrentar uma obra de porte considerável. A complexidade técnico-operacional de uma grande obra é muito maior. Tal complexidade cresce em progressão geométrica." 16

Longe de caracterizar exigência ilícita ou irrazoável, a necessidade de comprovação a partir da execução em até dois empreendimentos simultâneos é, me parece, decorrência natural da comprovação de capacidade operacional. Se se admite a exigência de capacitação para

\footnotetext{
${ }^{15}$ Como uma vez mais ensina Marçal: "A qualificação técnico-operacional consiste na execução anterior de objeto similar àquele licitado. Ora, isso significa que a identidade do objeto licitado é que determina a possibilidade ou não de somatório. Dá-se um exemplo: uma ponte de mil metros de extensão não é igual a duas pontes de quinhentos metros. Muitas vezes, a complexidade do objeto licitado deriva de certa dimensão quantitativa. Nesses casos, não terá cabimento o somatório de contratações anteriores." (Cf. JUSTEN FILHO, Marçal. Comentários à Lei de Licitações e Contratos Administrativos. 8. ed. São Paulo: Dialética, 2000. p. 338.).
}

A \& C R. de Dir. Administrativo e Constitucional, Belo Horizonte, ano 6, n. 24, p. 59-86, abr.jun. 2006 
operacionalizar empreendimentos de complexidade similar ao licitado, seria uma pantomima admitir como suficiente a demonstração de que o licitante acumulou ao longo do tempo as quantidades exigidas de atividades específicas.

Retirar a limitação no número de contratos ou a necessidade de simultaneidade seria, aí sim, aceitar exigências quantitativas írritas ao ordenamento vigente. Se queremos saber se um licitante já realizou uma atividade (uma técnica de engenharia, um serviço, o emprego de um material ou a execução de tarefa com tal ou qual característica), bastaria exigir a comprovação de que já a fez. Irrelevante seria saber se ele vem acumulando estas experiências ao longo do tempo, se ele já construiu cinqüenta veredas pavimentadas. Isso se confundiria com atestação técnicoprofissional cuja exigência de quantidades de experiências anteriores é vedada pelo artigo $30, \S 1^{\circ}$, I da Lei $n^{\circ} 8.666 / 93$.

A exigência de quantidades é admitida na atestação técnicooperacional pelo seu aspecto qualitativo (dimensão operacional do empreendimento executado) e só assim é porque se impede que se vá somando quantidades, desnaturando a complexidade operacional de tê-las realizado em um mesmo empreendimento ou ao menos em tempo simultâneo.

Tenho para comigo que a exigência de comprovação da execução em um ou alguns (poucos contratos), de forma simultânea, é absolutamente compatível com a natureza da capacidade técnico-operacional, que busca aferir aptidão gerencial e não conhecimento técnico específico nas atividades relevantes. E meu entendimento encontra respaldo na jurisprudência do E. Tribunal de Contas da União:

5.1. Na interpretação do artigo 30, inciso II, da Lei $\mathrm{n}^{\circ}$ 8.666/1993, feito por esta Corte de Contas, foi considerada legal a exigência de quantitativos mínimos para comprovação da qualificação técnico-operacional, que não deve se confundir com a qualificação técnico-profissional, para a qual é vedada a exigência de quantidades mínimas ou prazos máximos, conforme determina o artigo $30, \S 1^{\circ}$, inciso I, da mesma Lei, e é entendimento também da jurisprudência do TCU.

5.2. O caso em tela apresenta complexidade logística, pelo fato de a instalação ocorrer em várias estações e ainda pelo seu quantitativo. Assim, entendemos razoável o quantitativo exigido para a comprovação da capacidade operacional da empresa contratada para realizar tal serviço e que na exigência de comprovação em apenas um contrato a CBTU estava seguindo as orientações do Banco Mundial, que determina a comprovação de duas obras anteriores de natureza e complexidade equivalentes ao objeto do contrato pretendido. ${ }^{17}$

${ }^{16}$ DALLARI, Adilson. Licitação: Comprovação de Capacidade Técnico-Operacional. Revista Trimestral de Direito Público, 9/149, p. 152.

A \& C R. de Dir. Administrativo e Constitucional, Belo Horizonte, ano 6, n. 24, p. 59-86, abr.jun. 2006 
Ou ainda:

Quanto à exigência do mínimo de um atestado ou certidão, a exegese que fazemos do dispositivo editalício, contido no item c e no item "c.1", é a de que o administrador, impreterivelmente, requer a comprovação de cada uma das qualificações descritas nas parcelas, não importando se esta se faça sob a forma de um, dois ou mais atestados. O que o licitante deve observar é que a qualificação demonstrada para a parcela deve referir-se somente a um único projeto, visto ser-lhe defeso somar experiências anteriores com o intuito de aproximar-se dos quantitativos referenciados pelo TST em cada parcela.

Com isso, o órgão quer evitar que a habilitação tente ser produzida pelo somatório de aptidões parciais que, individualmente, sejam distoantes da experiência requerida. A título de exemplo do que ora afirmamos, imagine-se, por exemplo, não ser possível conceber a experiência de um construtor de 200 pontes de 5 metros para considerá-lo apto a executar projeto de ponte de 100 metros de comprimento. Tal impossibilidade é óbvia, tendo em vista que as circunstâncias estruturais, tecnológicas, técnicas, operacionais, que norteiam o projeto de uma grande ponte passa ao largo de pequenos projetos, mesmo que seu objeto tenha igual denominação. Por outro lado, já seria razoável admitir-se que o construtor de uma ponte de 50 a 70 metros tenha a capacidade mínima necessária para executar uma ponte de 100 metros.

De forma semelhante à do exemplo acima, entendemos estar agindo o órgão licitante ao exigir, em um único atestado, um mínimo de $50 \%$ das quantidades de cada parcela, para cada qual ele entende não ser possível exigir quantidade inferior, sob pena de prejudicar a qualidade da obra. ${ }^{18}$

Nenhuma dúvida tenho em sustentar a regularidade também dessa exigência.

3.4 Exigência de experiência limitada no tempo. A última das exigências que merece consideração se refere à imposição de comprovação de que as atividades listadas em anexo tenham sido realizadas num determinado intervalo de tempo (prazo máximo de $n$ meses). Aqui novamente estamos diante de exigência absolutamente aderente ao regime de comprovação da capacidade técnico-operacional. Antes, parágrafo 2.10, pude demonstrar que do ponto de vista operacional, o prazo de execução de uma obra ou serviço denota maior ou menor complexidade. Executar obra de vulto em largo prazo é, mesmo para o senso comum, mais simples do que realizá-la em curtíssimo lapso temporal. Nesta segunda situação, a mobilização haverá de ser maior, o recrutamento de pessoal mais agili-

17 TCU, Acórdão no 1.638/2004, Plenário, Relator Ministro Guilherme Palmeira, j. 20.10.2004.

${ }^{18}$ TCU, Acórdão no 1.513/2003, Plenário, Relator Ministro Adylson Motta, j. 08.10.2002.

A \& C R. de Dir. Administrativo e Constitucional, Belo Horizonte, ano 6, n. 24, p. 59-86, abr./jun. 2006 
zado, a logística mais sofisticada, o encadeamento das intervenções mais preciso, enfim, a operacionalização será mais complexa.

Sejam minhas as palavras de Carlos Ari Sundfeld para quem "não basta saber se a empresa é capaz de executar obra ou serviço com certa dimensão. É preciso, igualmente, verificar se é capaz de fazê-lo no prazo pretendido pela Administração. Para tanto, deve possuir capacidade técnico-operacional para, no tempo definido no edital, concluir a quantidade de obras e serviços objeto do certame. Para comprovar-se essa capacidade, o edital pode exigir a demonstração de experiência anterior na realização, em um dado prazo, de certa quantidade de obras e serviços." 19

Ora, se a licitação em apreço prevê que as intervenções deverão ser executadas num prazo de 6, 12 ou 18 meses, põe-se absolutamente razoável recrutar empresas que já tenham anteriormente se desempenhado das atividades que serão realizadas no futuro contrato em um cronograma compatível. Esta exigência será exatamente adequada a comprovar a capacidade operacional da empresa. Afinal, um licitante pode ter pavimentado $70.000 \mathrm{~m} 2$ de ruas num único contrato de plano de pavimentação comunitária que durasse 70 meses, asfaltando $1.000 \mathrm{~m} 2$ por mês. Isso não o fará capacitado a asfaltar $50.000 \mathrm{~m} 2$ em apenas 2 meses (caso a obra licitada justifique um ataque célere de recuperação asfáltica). No primeiro exemplo, o encargo poderia ter sido enfrentado com poucas máquinas, uma usina de asfalto, um quadro de trabalhadores enxuto. No segundo, presume-se a necessidade de mobilização de várias e diversificadas máquinas, talvez mais de uma usina de asfalto (ou uma usina de razoável capacidade produtiva, com todas as implicações disso decorrentes), um quadro de pessoal maior e mais bem treinado. Equiparar as duas experiências significa fazer tábula rasa da capacitação técnico-operacional, descurando da complexidade do empreendimento como um todo e preocupando-se apenas com as atividades isoladas e cumulativas.

Resgate-se o exemplo da Fórmula 1. As três atividades ali indicadas (troca de pneus, abastecimento de combustível, limpeza de pára-brisa) podem ser executadas por um simples frentista de posto. Realizá-las no prazo de alguns poucos segundos é o que a torna operacionalmente muito complexa. Poderia uma (a do frentista) substituir a outra (a da equipe)?

${ }^{19}$ Cf. SUNDFELD, Carlos Ari. Licitação e Contrato Administrativo: de acordo com as Leis 8.666/93 e 8.883/ 94. 2. ed. São Paulo:

A \& C R. de Dir. Administrativo e Constitucional, Belo Horizonte, ano 6, n. 24, p. 59-86, abr./jun. 2006 
Certamente que não.

Neste sentido é que encontramos jurisprudência do E. Superior Tribunal de Justiça:

ADMINISTRATIVO. LICITAÇÃO. INTERPRETAÇÃO DO ARTIGO 30, II, $\S 1^{\circ}$, DA LEI $N^{\circ} 8.666 / 93$. 1. Não se comete violação ao artigo 30, II, da Lei $\mathrm{n}^{\circ}$ 8.666/93, quando, em procedimento licitatório, exige-se comprovação, em nome da empresa proponente, de atestados técnicos emitidos por operadores de telefonia no Brasil de execução, no País, em qualquer tempo, de serviço de implantação de cabos telefônicos classe " $L$ " e " $C$ " em período consecutivo de 24 meses, no volume mínimo de $60.000 \mathrm{HXh}$, devidamente certificados pela entidade profissional competente. 2. "O exame do disposto no artigo 37, XXI, da Constituição Federal, em sua parte final, referente a "exigências de qualificação técnica e econômica indispensáveis à garantia do cumprimento das obrigações" revela que o propósito aí objetivado é oferecer iguais oportunidades de contratação com o Poder Público, não a todo e qualquer interessado, indiscriminadamente, mas, sim, apenas a quem possa evidenciar que efetivamente dispõe de condições para executar aquilo a que se propõe. (Adilson Dallari). 3. Mandado de segurança denegado em primeiro e segundo graus. 4. Recurso especial improvido. (STJ, REsp. 172.232/SP, Primeira Turma, Relator Ministro José Delgado, j. 17.08.1998)

A exigência de que a capacitação técnico-operacional se traduza em atestados demonstradores da execução de um rol de itens e quantidades num dado prazo é absolutamente compatível com a natureza da comprovação operacional. O tempo de execução predicará se houve ou não necessidade de uma expertise de mobilização, gerenciamento ou logística invulgar. Se a exigência de prazo for compatível com aquele cronograma previsto para o objeto licitado, nenhuma violação haverá ao regime legal. Tanto é que a redação do artigo $30, \S 1^{\circ}$, b, antes do veto presidencial (que não extirpou, já vimos, a possibilidade de atestação operacional) fazia expressa referência, como requisito de tal comprovação, a relação "quantitativo / prazo global", justamente porque o legislador via aí um importante elemento para se aferir a capacidade da licitante organizar as diversas dimensões do empreendimento (o que afinal há de ser objeto desta comprovação).

3.5 Temos, portanto, que as três exigências contidas no item impugnado não constituem exorbitância ou abuso que lhes torne írritas ao ordenamento jurídico. Contudo, em face dos elementos informativos que me foram trazidos, depreende-se que o Egrégio Tribunal de Contas teria manifestado sua censura não a cada exigência em particular, mas ao conjunto delas ou seja à sobreposição das três ordens de requisitos (execução das parcelas indicadas como relevantes em obra rodoviária, em A\& C R. de Dir. Administrativo e Constitucional, Belo Horizonte, ano 6, n. 24, p. 59-86, abr./jun. 2006 
até dois contratos simultâneos e contidas em um dado prazo), o que as faria contrariar o artigo $30, \S 5^{\circ}$.

Não parece cabente a preocupação. É exatamente a conjugação destes fatores que dá a característica de qualificação técnico-operacional. Pressuponho, repito, que o rol de atividades e quantidades arroladas em anexo ao edital sejam plausíveis (o que pressuponho haja vista a manifestação do TCE não censurá-las nem sob o prisma qualitativo — relevância para o objeto - nem quantitativo - proporção em face dos quantitativos do projeto). Ora, exigir que estas atividades tenham sido realizadas em sede de obras de características rodoviárias, que digam respeito a um só empreendimento ou a no máximo dois executados a um só tempo e com um cronograma compatível com o do futuro contrato (relação quantitativos / prazo global a que aludia o texto original da lei de licitações), é exatamente perseguir capacidade operacional compatível com objeto licitado. É exatamente a articulação destas exigências que torna relevante a exigência de capacitação técnico-operacional, pois que, se o pretendido fosse apurar experiências esparsas — executadas alhures —, bastaria a comprovação de capacidade técnico-operacional.

3.6 Portanto, assim analisadas as exigências, não tenho razão por ver nelas qualquer ilicitude, qualquer irrazoabilidade, qualquer abuso apto a torná-las contrárias ao regime contido na Lei $n^{\circ}$ 8.666/93. Diante do objeto licitado, tais exigências passam perfeitamente no crivo de proporcionalidade.

São tais exigências úteis, pois servem a afastar licitantes que não demonstrem capacidade operacional específica a fazer frente à execução do contrato. São necessárias, pois a urgência dos reparos e melhorias nas rodovias estaduais não concedidas não admite interrupções ou dificuldades de execução, fazendo imperativo um cronograma rigoroso e certa eficiência operacional, o que exige cautelas de qualificação mais rigorosas. Por fim, as exigências são adequadas e ponderadas, vez que as quantidades exigidas, vê-se da documentação que instrui o presente estudo, giram em torno de 50 a $60 \%$ dos quantitativos previstos para o Contrato licitado.

Tenho comigo serem perfeitamente hígidas as exigências em apreço.

\section{0 respeito ao artigo $30, \S 5^{\circ}$, da Lei $n^{\circ} 8.666 / 93$}

4.1 Antes de concluir, rápido comentário a respeito de uma possível afronta ao disposto no $\S 5^{\circ}$ do artigo 30 da Lei $n^{\circ} 8.666 / 93$. Diz o 
dispositivo:

$\S 5^{\circ}$. É vedada a exigência de comprovação de atividade ou de aptidão com limitações de tempo ou de época ou ainda em locais específicos, ou quaisquer outras não previstas nesta Lei, que inibam a participação na licitação.

Algumas notas hermenêuticas se fazem necessárias.

4.2 Primeiro, as referidas limitações de tempo ou de época de execução. Elas não impedem que se exija, para capacitação técnico-operacional, que as quantidades exigidas tenham sido executadas num determinado intervalo de tempo (prazo global de execução). Elas impedem sim que se exija a realização das atividades objeto de atestação nos últimos x meses ou nos idos de tanto a tanto do calendário gregoriano. Uma coisa é exigir que o empreendimento tenha sido executado no prazo máximo de tanto (requisito de eficiência, predicado de maior mobilização, etc), pouco importando se isso se deu há um ano ou há uma década. Outra coisa, bastante diferente, é excluir experiências mais recentes ou mais vetustas. No primeiro caso, há plausibilidade para a aferição de expertise operacional. No segundo não há qualquer razão. Por isso a lei admite aquela e veda (exatamente no $\S 5^{\circ}$ do artigo 30) esta.

Tanto a vedação a exigências de limitação de tempo ou época não significa proibição de requisitos de prazo de execução que o inciso II do mesmo artigo 30, determina que se deverá exigir “comprovação de aptidão para desempenho de atividade pertinente e compatível em características, quantidades e prazos com o objeto da licitação, e indicação das instalações e do aparelhamento e do pessoal técnico adequados e disponíveis para a realização do objeto da licitação, bem como da qualificação de cada um dos membros da equipe técnica que se responsabilizará pelos trabalhos".

Dúvida, pois, não deve restar que a vedação a exigências de tempo e época não se confunde com requisito de prazo de execução, ainda que esta atividade, com cronograma compatível, tenha sido realizada há muitos e muitos anos.

4.3 O mesmo se diga quanto à vedação de comprovação de execução em locais específicos. Esta proibição se refere, por óbvio, à exigência de delimitação, de circunscrição, da experiência anterior a uma localidade, a um sítio geográfico escolhido discricionariamente sem qualquer nexo de relação com as características do objeto a ser executado. Tal norma do 
$\S 5^{\circ}$ impediria que a exigência se referisse a obras realizadas no Brasil, no Estado de São Paulo, ou na cidade de Sorocaba. Isso seria exigência de realização em local específico ao arrepio da lei.

Contudo, a regra do $\S 5^{\circ}$ não significa interdição de exigências atinentes às características da atividade. A exigência de serem as obras realizadas em uma rodovia não diz com o local em que elas foram executadas, mas com as características específicas das obras, sua natureza, como anteriormente procurei demonstrar.

Como já ensinou certa vez o Ministro Eros Grau, o Direito não se interpreta em tiras, aos pedaços. A exegese do $\S 5^{\circ}$ deve ser tomada em cotejo com outros dispositivos. E no $§ 3^{\circ}$ deste mesmo artigo 30 vemos que "[s]erá sempre admitida a comprovação de aptidão através de certidões ou atestados de obras ou serviços similares de complexidade tecnológica e operacional equivalente ou superior".

Portanto, a expressão "locais específicos" contida no $§ 5^{\circ}$ só pode ser entendida como vedando exigências de localização geográfica das atividades atestadas sem qualquer relação pertinente com as suas características.

4.4 Por fim, resta a locução derradeira contida no dispositivo, que diz serem vedadas exigências "que inibam a participação na licitação". Espero ter demonstrado que qualquer exigência de habilitação restringe (inibe, portanto) a participação dos interessados. Não é isso que importa. Releva saber se a exigência é razoável e justificável.

Tenho portanto que o $\S 5^{\circ}$ deve ser interpretado em conjugação com o artigo $3^{\circ}, \S 1^{\circ}$, I, da mesma Lei $n^{\circ} 8.666 / 93$. Diz o dispositivo:

$\S 1^{\circ}$. É vedado aos agentes públicos:

I - admitir, prever, incluir ou tolerar, nos atos de convocação, cláusulas ou condições que comprometam, restrinjam ou frustrem o seu caráter competitivo e estabeleçam preferências ou distinções em razão da naturalidade, da sede ou domicílio dos licitantes ou de qualquer outra circunstância impertinente ou irrelevante para o específico objeto do contrato.

Segue daí que as exigências inibidoras à participação dos interessados que são vedadas pelo $\S 5^{\circ}$ do artigo 30 serão aquelas que não guardem relação de pertinência ou relevância para o objeto do contrato, nos termos do que prediz o artigo $31, \S 1^{\circ}$, I da própria Lei.

4.5 Nestes quadrantes, e consoante tudo que pude asseverar anteriormente, não vejo como o artigo $30, \S 5^{\circ}$, pode ser óbice á aprovação das exigências de qualificação técnico-operacional inseridas nos editais da A \& C R. de Dir. Administrativo e Constitucional, Belo Horizonte, ano 6, n. 24, p. 59-86, abr./jun. 2006 
análise que, nestes termos, estão em absoluta consonância com a legislação de regência.

\section{Síntese e resposta objetiva ao quesito}

5.1 Chego ao final certo de que as exigências de qualificação técnicooperacional previstas nas peças convocatórias, à luz do específico objeto das licitações, estão em absoluta conformidade com a lei.

5.2 Embora não haja hierarquia entre espécies de capacitações, há uma clara distinção entre a capacidade técnico-profissional e a capacidade técnico operacional, na medida em que cada qual se presta a demonstrar uma capacitação distinta e não suprível pela outra.

5.3 Ao exigir a comprovação da capacidade técnico profissional, visa o poder público a aferir a detenção de conhecimentos técnicos específicos sobre as distintas atividades integrantes do objeto licitado de modo a verificar se há o domínio dos conhecimentos especializados (mesmo que fragmentários) de como se executa cada etapa da obra, do serviço ou do fornecimento que se quer ver realizado no futuro contrato.

5.4 Já no que tange à comprovação da capacidade técnico operacional se procura aferir se a empresa possui a aptidão para realizar o todo em complexidade e especificidade compatível com o que se alvitra no futuro contrato, é dizer, a capacidade gerencial, organizacional, logística e de gestão de um empreendimento dotado de alguma complexidade.

5.5 Pela sua própria natureza, a aferição da capacidade operacional da licitante para a execução do empreendimento objeto do certame só é possível mediante a exigência de especificações de prazo, local, quantidades e outras características qualitativas. É exatamente a conjugação destes fatores que dá a característica de qualificação técnico-operacional, já que o que se busca é aferir aptidão gerencial e não conhecimento técnico específico nas atividades relevantes. Por isso, justificam-se tanto a exigência de serem os atestados apresentados relativos a obras rodoviárias, como a de terem as obras atestadas sido executadas em até dois contratos simultâneos, como ainda a exigência relativa ao prazo máximo de sua duração.

5.6 É legal a exigência relativa à localização das atividades de comprovação obrigatória (realizadas em rodovias) porque obras urbanas e empreitadas rodoviárias possuem complexidades distintas. Não valendo a experiência na realização das primeiras como comprovação de capacidade operacional com relação às segundas.

A \& C R. de Dir. Administrativo e Constitucional, Belo Horizonte, ano 6, n. 24, p. 59-86, abr./jun. 2006 
5.7 Também é legal a exigência de que os quantitativos tenham sido realizados em até dois contratos executados simultaneamente, já que nenhuma serventia teria para os fins da capacidade operacional a demonstração da execução isolada de todos os itens relevantes do objeto licitado.

5.8 O mesmo se diga também sobre a imposição de comprovação de que as atividades listadas em anexo tenham sido realizadas num determinado intervalo de tempo, já que executar obra de vulto em largo prazo é sabidamente mais simples do que realizá-la em curtíssimo lapso temporal.

5.9 Assim entendendo, dou a seguinte resposta ao quesito adrede formulado:

1. A exigência de qualificação técnica inserida nos editais para contratação de obras de melhorias rodoviárias correspondente à demonstração de experiência anterior na execução de itens de serviços realizados em obras rodoviárias, simultaneamente em número limitado de contratos e em período determinado é compatível com o regime da Lei de Licitações, especialmente com o seu artigo $30, \S 5^{\circ}$ ?

Sim. A exigência á absolutamente compatível. Os requisitos de execução em no máximo dois contratos, executados simultaneamente, em obras rodoviárias e em prazo global limitado a número de meses compatível com o cronograma do contrato objeto da licitação são absolutamente compatíveis com exigências de capacitação técnico-operacional, encontrando respaldo na lei (artigo 30, $3^{\circ}$ ), na doutrina e na jurisprudência (das Cortes judiciais e de contas). $\mathrm{O} \S 5^{\circ}$ do artigo 30 nenhum óbice apresenta às referidas exigências, pois elas não implicam em limitação de tempo ou época (mas apenas em requisito de prazo, admitido pelo artigo 30, II); nem de local específico (pois o requisito de obra rodoviária não é exigência geográfica, mas característica do tipo de obra), nem tampouco restrição írrita, pois dizem respeito a condições absolutamente pertinentes e relevantes para o objeto da licitação (artigo $3^{\circ}, \S 1^{\circ}$, I, Lei no $8.666 / 93$ ).

Informação bibliográfica deste texto, conforme a NBR 6023:2002 da Associação Brasileira de Normas Técnicas (ABNT):

MARQUES NETO, Floriano de Azevedo. Limites conceituais às exigências de capacitação técnico-operacional em licitações. A\&C Revista de Direito Administrativo e Constitucional, Belo Horizonte, ano 6, n. 24, p. 59-86, abr./jun. 2006.

A \& C R. de Dir. Administrativo e Constitucional, Belo Horizonte, ano 6, n. 24, p. 59-86, abr./jun. 2006 
A \& C R. de Dir. Administrativo e Constitucional, Belo Horizonte, ano 6, n. 24, p. 59-86, abr.jun. 2006 